\title{
Модификация спектров фотопроводимости в композитных структурах ZnO-квантовые точки CdSe под действием дополнительного фотовозбуждения
}

\author{
(C) К.А. Дроздов ${ }^{1}$, И.В. Крылов ${ }^{1}$, А.С. Чижов ${ }^{2}$, М.Н. Румянцева ${ }^{2}$, \\ Л.И. Рябова ${ }^{2}$, Д.Р. Хохлов \\ ${ }^{1}$ Московский государственный университет им. М.В. Ломоносова (физический фракультет), \\ 119991 Москва, Россия \\ ${ }^{2}$ Московский государственный университет им. М.В. Ломоносова (химический факультет), \\ 119991 Москва, Россия \\ ฯ E-mail: khokhlov@mig.phys.msu.ru
}

(Получена 6 декабря 2017 г. Принята к печати 15 декабря 2017 г.)

Внедрение в пористую матрицу $\mathrm{ZnO}$ нанокристаллов CdSe приводит к сенсибилизации композита в видимом спектральном диапазоне. Измерение спектральных зависимостей фотопроводимости при варьируемой внешней подсветке показало, что они могут претерпевать обратимые изменения. Показано, что форма пика и положение локального максимума фотопроводимости, отвечающего нанокристаллам, зависят от спектрального распределения интенсивности падающего излучения. Обсуждаются механизмы, ответственные за процесс.

DOI: $10.21883 /$ FTP.2018.07.46049.8788

\section{1. Введение}

Широкозонные оксиды $\left(\mathrm{In}_{2} \mathrm{O}_{3}, \mathrm{ZnO}, \mathrm{SnO}_{2}\right)$ являются базовыми материалами для создания различных приборов и устройств, используемых в энергетике (солнечные батареи), мониторинге состава окружающей среды (газовые датчики), прозрачных электродах для оптоэлектронных систем [1-3]. Каждое из перечисленных направлений предъявляет набор требований к рабочим параметрам соответствующих устройств. Поэтому важно иметь возможность направленно менять эти параметры, приводя их в соответствие с оптимальными значениями. Одни из основных параметров газового датчика - чувствительность и быстродействие во многом определяются процессами десорбции захваченных на поверхность атомов. Традиционный подход предполагает разогрев структуры до $200-300^{\circ} \mathrm{C}$. Данный метод порождает набор неустранимых проблем, таких как высокое энергопотребление, относительно малый срок эксплуатации и ограниченность миниатюризации вследствие необходимости эффективного отвода тепла [4].

Таким образом, актуальной является проблема создания альтернативного газового датчика и детальное исследование процессов, обусловливающих его функционирование, для максимальной оптимизации системы. Одним из наиболее перспективных подходов является использование излучения ультрафиолетовой или видимой области спектра для стимуляции процессов десорбции. В первом случае предполагается использовать излучение с энергией фотонов, превышающей ширину запрещённой зоны $\mathrm{In}_{2} \mathrm{O}_{3}, \mathrm{ZnO}, \mathrm{SnO}_{2}$ [5,6], во втором создание композитной структуры на основе исходных широкозонных оксидов с фотосенсибилизатором, чувствительным в видимом спектральном диапазоне [7,8].
Цель настоящей работы - исследование стабильности спектральных свойств композита на основе $\mathrm{ZnO}$ c внедренными нанокристаллами CdSe при засветке в видимом и ультрафиолетовом спектральных диапазонах.

\section{2. Методика эксперимента и исследованные образцы}

Синтез нанокристаллического оксида цинка проведен методом осаждения из водного раствора $\mathrm{Zn}\left(\mathrm{CH}_{3} \mathrm{COO}\right)_{2}$ с использованием водного раствора $\mathrm{NH}_{4} \mathrm{HCO}_{3}$ при $50^{\circ} \mathrm{C}$ [9]. Осадок сушили при $50^{\circ} \mathrm{C}$ в течение 24 ч и отжигали на воздухе при $300^{\circ} \mathrm{C}$ в течение 24 ч. Фазовый состав и параметры микроструктуры $\mathrm{ZnO}$ определены методами рентгеновской дифракции и просвечивающей электронной микроскопии. Установлено, что полученный оксид цинка имеет структуру вюрцита, образован частицами размером 14-15 нм, объединенными в агломераты (рис. 1,a).

Нанокристаллы CdSe размером $2.8 \pm 0.2$ нм синтезированы высокотемпературным коллоидным методом с использованием олеиновой кислоты в качестве стабилизатора [10] Размер квантовых точек определен из данных спектроскопии видимого поглощения по калибровке, приведенной в работе [11], и из данных просвечивающей электронной микроскопии (рис. $1, b$ ).

Для проведения измерений фотопроводимости формирование нанокомпозитов производили непосредственно на микроэлектронном чипе [7,8]. Порошок $\mathrm{ZnO}$ смешивали со связующим веществом (раствор терпениола в этаноле), в виде пасты наносили на микроэлектронный чип, представляющий собой подложку $\mathrm{Al}_{2} \mathrm{O}_{3}$ с платиновыми нагревателем и контактами, и отжигали 

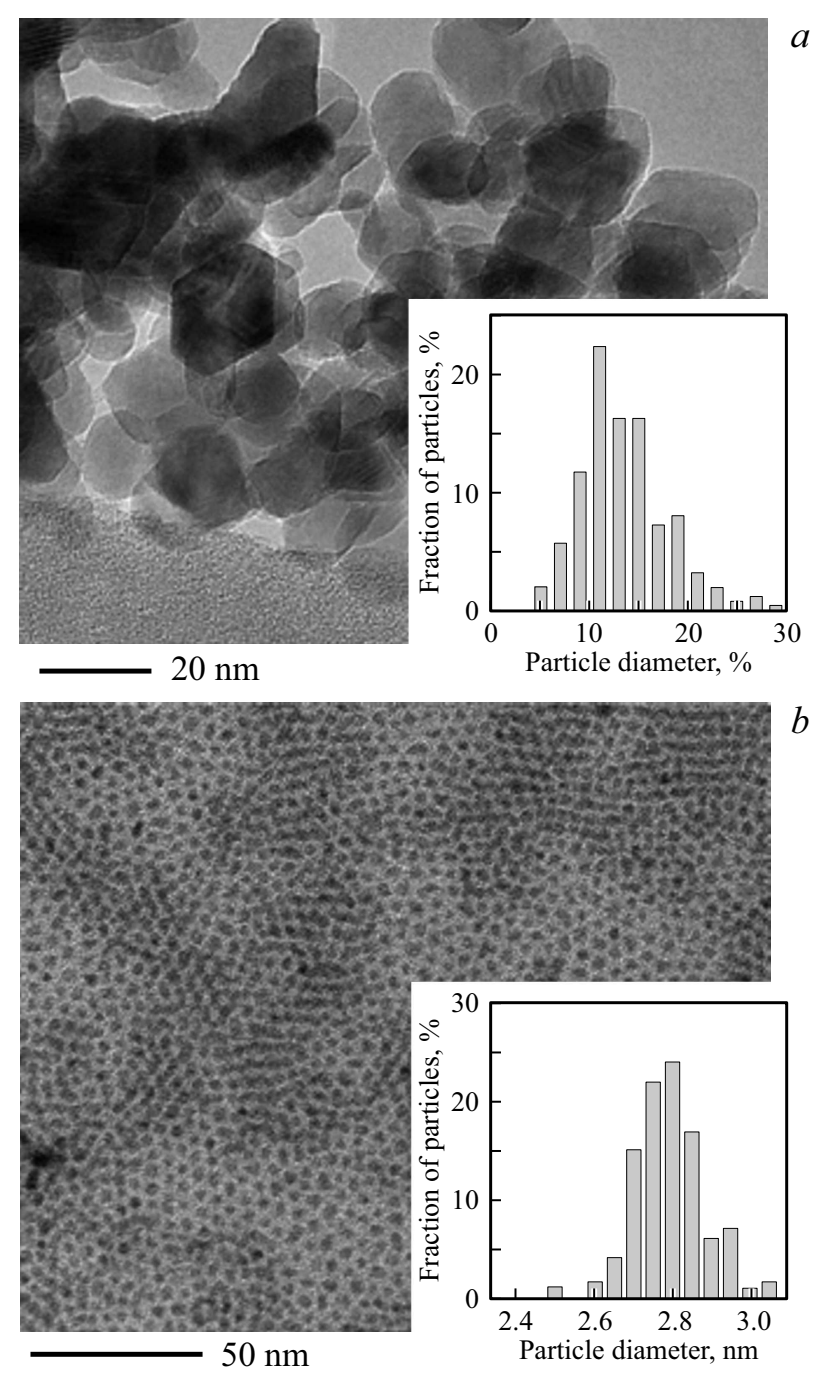

Pис. 1. Данные просвечивающей электронной микроскопии для кристаллитов матрицы $\mathrm{ZnO}(a)$ и нанокриталлов CdSe $(b)$. На вставках указано распределение частиц по размеру.

при $300^{\circ} \mathrm{C}$ в течение 24 ч для удаления связующего. Массу полученных толстых пленок $\mathrm{ZnO}$ контролировали с точностью \pm 0.1 мг. Для получения нанокомпозитов $\mathrm{ZnO}-\mathrm{CdSe}$ на поверхность пленок наносили золь, содержащий стабилизированные олеиновой кислотой нанокристаллы $\mathrm{CdSe}$ в гексане $\left(4.5 \cdot 10^{-4} \mathrm{M}\right)$. Объем введенного золя рассчитывали таким образом, чтобы массовая доля $\mathrm{CdSe}$ в нанокомпозите составила $5 \%$.

Матрица $\mathrm{ZnO}$ и композиты на ее основе имели электронную проводимость. Кинетика и спектры фотопроводимости исследованы при комнатной температуре. В качестве дополнительной подсветки использовались светодиоды с одинаковой мощностью светового потока и максимумом излучения на длинах волн $\lambda$, отвечающих собственному оптическому поглощению широкозонной матрицы $\mathrm{ZnO}$ (380 нм) и первому экситонному максимуму для нанокристаллов $\mathrm{CdSe}(530$ нм).

\section{3. Результаты измерений}

Типичные зависимости кинетики относительного сигнала фотопроводимости $\sigma / \sigma_{0}\left(\sigma_{0}-\right.$ проводимость в темновых условиях) для структур с квантовыми точками показаны на рис. 2. Величина фотоотклика, время выхода на насыщение и скорость релаксации проводимости к равновесному значению после выключения подсветки зависят от длины волны излучения накачки.

Поскольку релаксационные процессы имеют задержанный характер, для регистрации спектров фотопроводимости использовалась определенная методика [12]. Образец засвечивался в течение 20 с, а временной интервал между двумя последовательными измерениями составлял 30 мин. При использовании дополнительной подсветки светодиодом образец перед началом измерений засвечивался в течение 90 мин; во время проведения спектральных измерений дополнительная подсветка не
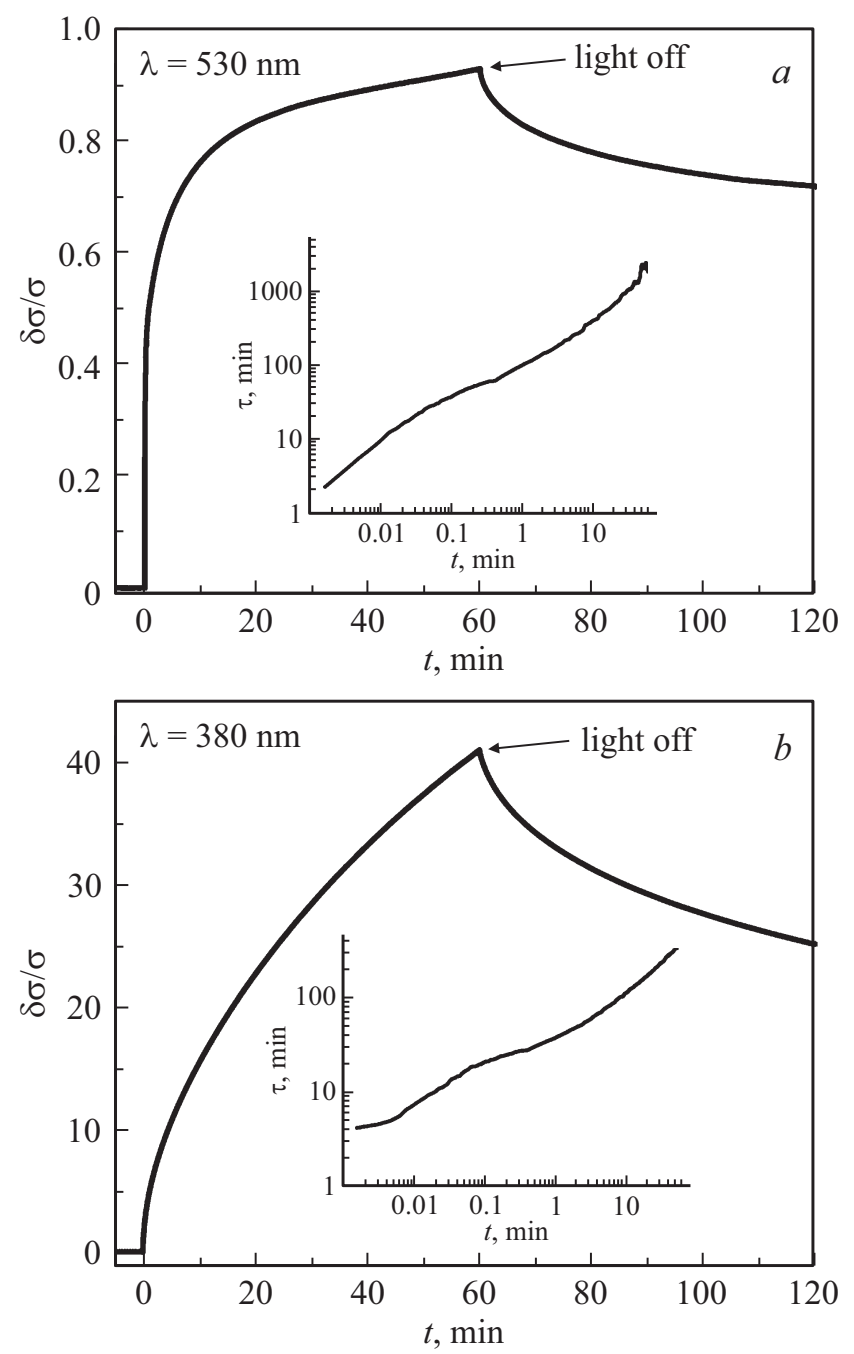

Рис. 2. Кинетика фотопроводимости $\sigma / \sigma_{0}$ структур $\mathrm{ZnO}-\mathrm{CdSe}$. Длина волны источника излучения указана у кривых. На вставках к рисункам представлены кинетики изменения мгновенного времени жизни $\tau$, характеризующего спад фотопроводимости после выключения подсветки. 


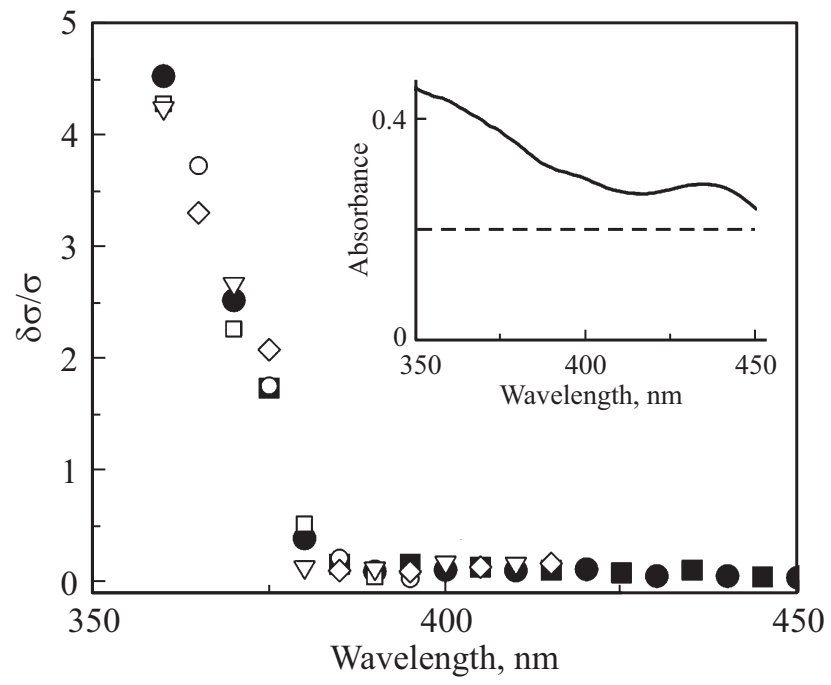

Рис. 3. Спектры фотопроводимости для структур $\mathrm{ZnO}-\mathrm{CdSe}$ в темновых условиях (открытые символы) и в условиях подсветки светодиодом (закрашенные символы). Длина волны диода $\lambda=530$ нм. Разные символы отвечают разным дням проведения эксперимента. На вставке представлено оптическое поглощение нанокристаллов $\mathrm{CdSe}$ без дополнительной подсветки в том же спектральном диапазоне. Пунктиром отмечена амплитуда поглощения на длине волны 530 нм.

отключалась. Спектральные зависимости снимались в несколько приемов, интервал между экспериментами составлял не менее 48 ч.

На рис. 3 представлены спектральные зависимости фотопроводимости для композитной структуры $\mathrm{ZnO}-\mathrm{CdSe}$ в темновых условиях и при непрерывной подсветке на длинах волн $\lambda=530$ нм. Подсветка на данных длинах волн не приводит к сколь-либо существенному изменению спектральных характеристик, отвечающих краю собственного поглощения $\mathrm{ZnO}$.

На рис. 4 представлены спектральные зависимости оптического поглощения нанокристаллов CdSe (рис. 4, a), фотопроводимости структуры $\mathrm{ZnO}-\mathrm{CdSe}$ в темновых условиях (рис. 4, $b$ ) и при непрерывной подсветке на длинах волн $\lambda=380$ нм (рис. 4,c). Все спектральные зависимости фотопроводимости демонстрируют особенности, отвечающие оптическому поглощению нанокристаллов CdSe в гексане. При использовании непрерывной засветки амплитуда пика в спектрах фотопроводимости существенно уменьшается, что связано с наличием поглощения на длинах волн $\lambda$ в нанокристаллах $\mathrm{CdSe}$. Необходимо отметить, что положение максимумов и форма пиков в спектрах поглощения квантовых точек в гексане и в спектрах фотопроводимости для структур $\mathrm{ZnO}-\mathrm{CdSe}$ несколько отличаются. Пик в спектрах фотопроводимости при непрерывной подсветке почти полностью отвечает собственному поглощению нанокристаллов в гексане. При отсутствии подсветки пик фотопроводимости существенно уширен, его положение максимума смещено в сторону меньших длин волн.
Важно, что все экспериментальные данные, представленные на рис. 3 и 4, демонстрируют хорошую воспроизводимость при проведении серии измерений, разнесенных по времени.
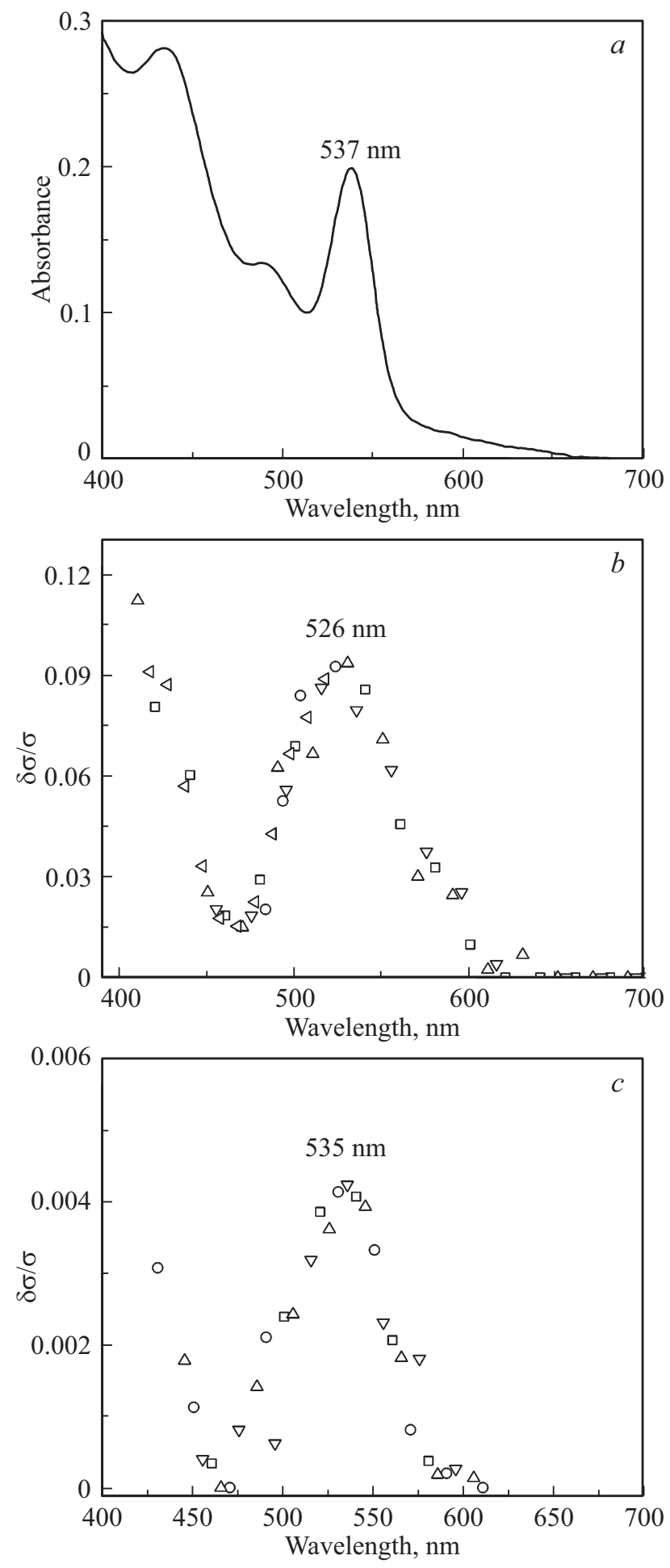

Pис. 4. Спектр поглощения нанокристаллов $\mathrm{CdSe}(a)$, фотопроводимости структуры $\mathrm{ZnO}-\mathrm{CdSe}$ в темновых условиях $(b)$ и в условиях подсветки светодиодом $\lambda=380$ нм (c). Разные символы на рис. 4, $b, c$ отвечают различным дням проведения эксперимента. 


\section{4. Обсуждение результатов}

В композитных структурах на основе $\mathrm{ZnO}$ с внедренными нанокристаллами CdSe может наблюдаться несколько механизмов генерации и рекомбинации носителей заряда.

Подсветка структуры $\mathrm{ZnO}-\mathrm{CdSe}$ с энергией фотонов, превышающей ширину запрещенной зоны $\mathrm{ZnO}(\lambda<380 \mathrm{Hм})$, обеспечивает межзонную генерацию электронно-дырочных пар. Транспорт носителей в пористых пленках определяется модуляцией зонного рельефа неоднородной полупроводниковой матрицы и наличием в энергетическом спектре рекомбинационного и дрейфового барьеров [13]. Установление квазиравновесия в системе при включении подсветки является долговременным процессом. Задержанный характер спада фотопроводимости определяется рекомбинационным барьером.

Подсветка структуры $\mathrm{ZnO}-\mathrm{CdSe}$ с энергией фотонов, превышающей расстояние между нижним электронным и верхним дырочным уровнями в $\mathrm{CdSe}(\lambda<540 \mathrm{Hм})$, обеспечивает генерацию электронно-дырочных пар в нанокристаллах с последующей локализацией дырок в квантовых точках и инжекцией электронов из квантовых точек в объем матрицы (туннельный механизм переноса). Процесс рекомбинации идет за счет захвата электрона из объема матрицы в нанокристалл. В силу дискретности энергетического спектра квантовой точки для туннелирования необходимо, чтобы электрон обладал энергией, отвечающей свободному от электронов уровню.

Матрица $\mathrm{ZnO}$ нефоточувствительна на длинах волн $\lambda=530$ нм. Кинетику фотопроводимости, полученную при подсветке композита $\mathrm{ZnO}-\mathrm{CdSe}$ на данных длинах волн (рис. 2,a), можно однозначно соотнести с вкладом от нанокристаллов CdSe. Подсветка композита в более коротковолновой области $(\lambda=380$ нм $)$ приводит к увеличению амплитуды фотоотклика более чем на порядок и существенному увеличению времени достижения квазистационарного состояния (рис. 2, $a$ ). При этом амплитуда поглощения нанокристаллов $\mathrm{CdSe}$ на длинах волн 380 и 530 нм отличается менее чем в 2 раза (см. вставку к рис. 3). Кроме того, в спектральных зависимостях фотопроводимости композита $\mathrm{ZnO}-\mathrm{CdSe}$ вблизи края собственного поглощения $\mathrm{ZnO}$ не наблюдается сколь-либо существенного вклада от нанокристаллов CdSe (рис. 3). Совокупность данных факторов позволяет утверждать, что кинетика фотопроводимости при подсветке композита $\mathrm{ZnO}-\mathrm{CdSe}$ на длинах волн $\lambda=380$ нм (рис. $2, b$ ) в основном обусловлена процессами межзонной генерации и рекомбинации в матрице $\mathrm{ZnO}$. Длительное достижение квазистационарного состояния при межзонной генерации можно связать с эффективными рекомбинационными процессами. Мгновенные времена релаксации $\tau=\sigma_{s} /|d \sigma / d t|\left(\sigma_{s}-\right.$ проводимость в стационарном состоянии), характеризующие спад проводимости, могут быть описаны зависимостью $\tau(t) \propto t^{\alpha}$, где $\alpha$ принимает значения 0.38 и 0.27 для рекомбинации в нанокристаллах
$\mathrm{CdSe}$ (см. вставку на рис. $2, a)$ и межзонной рекомбинации (см. вставку на рис. 2,a) соответственно. Как известно из литературных данных [14], рекомбинации на центрах захвата в неоднородных полупроводниках характеризуются значениями $\alpha$, близкими к 1. При рекомбинации в нанокристаллах $\mathrm{CdSe}$ отличие $\alpha$ от 1 может быть обусловлено сложным механизмом захвата фотовозбужденных электронов из матрицы в квантовую точку (комбинация активационного и тоннельного механизмов). Для межзонной рекомбинации в $\mathrm{ZnO}-$ пространственным разделением фотовозбужденных носителей заряда за счет захвата и локализации дырок в нанокристаллах $\mathrm{CdSe}$.

Спектральные зависимости фотопроводимости композита $\mathrm{ZnO}-\mathrm{CdSe}$ в диапазоне длин волн 400-700 нм могут быть обусловлены поглощением внедренных нанокристаллов и уровней, связанных с поверхностью и дефектами в матрице (рис. 4,b). Согласно имеющимся литературным данным, внедрение квантовых точек в пористую матрицу может приводить к спектральному сдвигу особенностей спектров, отвечающих квантовым точкам, как в сторону бо́льших, так и в сторону меньших длин волн. В качестве возможных причин сдвига в [12] приводится влияние матрицы на исходный энергетический спектр квантовых точек и уменьшение эффективного размера точек вследствие окисления их поверхности. В настоящей работе помимо сдвига положения максимума, отвечающего квантовым точкам, наблюдаются существенное уширение самого пика и изменение его формы (рис. 4, $a, b$ ). При этом при непрерывной подсветке на длине волны 380 нм ширина пика в спектре фотопроводимости существенно уменьшается, а его форма и положение максимума намного лучше воспроизводят пик поглощения нанокристаллов в гексане (рис. 4, a,c). Данный эффект может быть объяснен изменением состояния поверхности матрицы вблизи квантовой точки при подсветке [15]. Локализованная в нанокристалле фотовозбужденная дырка может участвовать в процессе десорбции за счет рекомбинации с электроном, захваченным адсорбированным атомом или молекулой $[7,8]$. Это приводит к изменению зарядового окружения самого нанокристалла и исчезновению в энергетическом спектре матрицы $\mathrm{ZnO}$ дополнительных уровней, связанных с адсорбированными атомами.

Важно отметить, что изменение спектральных зависимостей композита $\mathrm{ZnO}-\mathrm{CdSe}$ при подсветке является полностью обратимым процессом. После длительной (несколько дней) релаксации спектральные зависимости фотопроводимости композита возвращаются к темновым значениям, приведенным на рис. $4, b$.

\section{5. Заключение}

Исследованы спектральные зависимости поглощения квантовых точек $\mathrm{CdSe}$, спектры фотопроводимости и кинетика задержанной фотопроводимости композита 
$\mathrm{ZnO}-\mathrm{CdSe}$ при дополнительной подсветке на длинах волн, отвечающих собственному поглощению матрицы $\mathrm{ZnO}$ и положению первого экситонного максимума CdSe.

Под действием внешнего излучения концентрация носителей заряда в матрице может изменяться за счет межзонной генерации в $\mathrm{ZnO}$ и инжекции из нанокристаллов $\mathrm{CdSe}$. При внедрении нанокристаллов CdSe в матрицу происходит необратимая модификация их спектральных характеристик. Экспериментально подтверждено, что под воздействием внешней подсветки может также происходить обратимая модификация спектральных характеристик. Подсветка модифицирует характер зарядового обмена между матрицей и нанокристаллом и является одним из факторов, которые могут влиять на сенсорные свойства всего композита.

Следует также отметить, что дополнительное фотовозбуждение не приводит к появлению сколько-нибудь заметного фотоотклика на длинах волн, существенно превышающих 535 нм, при том что проводимость может изменяться в десятки раз. Таким образом, можно констатировать, что само по себе появление задержанной фотопроводимости, например в неоднородных композитных структурах, исследованных в настоящей работе, не свидетельствует о наличии локальных электронных состояний, привязанных в квазиуровню Ферми, о которых сообщалось в работах $[16,17]$ в применении к легированным узкощелевым полупроводникам на основе теллурида свинца.

Работа выполнена при поддержке гранта РНФ № 16-12-10071.

\section{Список литературы}

[1] D.V. Talapin, J.-S. Lee, M.V. Kovalenko, E.V. Shevchenko. Chem. Rev., 110, 389 (2010).

[2] Р.Б. Васильев, Л.И. Рябова, М.Н. Румянцева, А.М. Гаськов. Успехи химии, 73 (10), 1019 (2004).

[3] P.V. Kamat. J. Phys. Chem. C, 112, 18737 (2008).

[4] J.D. Prades, R.J. Diaz, F. Hernandez-Ramirez, S. Barth, A. Cirera, A. Romano-Rodriguez, S. Mathur, J.R. Morante. Sensors Actuators B: Chem., 140, 337 (2009).

[5] S. Mishra, C. Ghanshyam, N. Ram, R.P. Bajpai, R.K. Bedi. Sensors Actuators B: Chem., 97, 387 (2004).

[6] B.P.J. de Lacy Costello, R.J. Ewen, N.M. Ratcliffe, M. Richards. Sensors Actuators B: Chem., 134, 945 (2008).

[7] A.S. Chizhov, M.N. Rumyantseva, R.B. Vasiliev, D.G. Filatova, K.A. Drozdov, I.V. Krylov, A.M. Abakumov, A.M. Gaskov. Sensors Actuators B: Chemical, 205, 305 (2014).

[8] A. Chizhov, M. Rumyantseva, R. Vasiliev, D. Filatova, K. Drozdov, I. Krylov, A. Marchevsky, O. Karakulina, A. Abakumov, A. Gaskov. Thin Sol. Films, 618, 253 (2016).

[9] N. Vorobyeva, M. Rumyantseva, D. Filatova, E. Konstantinova, D. Grishina, A. Abakumov, S. Turner, A. Gaskov. Sensors Actuators B: Chemical, 182, 555 (2013).

[10] R. Vasiliev, A. Babynina, O. Maslova, M. Rumyantseva, L. Ryabova, A. Dobrovolsky, K. Drozdov, D. Khokhlov, A. Abakumov, A. Gaskov. J. Mater. Chem. C, 1, 1005 (2013).
[11] W.W. Yu, L. Qu, W. Guo, X. Peng. Chem. Mater., 15 (14), 2854 (2003).

[12] К.А. Дроздов, В.И. Кочнев, А.А. Добровольский, Р.Б. Васильев, А.В. Бабынина, М.Н. Румянцева, А.М. Гаськов, Л.И. Рябова, Д.Р. Хохлов. ФТП, 47 (3), 360 (2013).

[13] Р.Б. Васильев, С.Г. Дорофеев, М.Н. Румянцева, Л.И. Рябова, А.М. Гаськов. ФТП, 40 (1), 108 (2006).

[14] М.К. Шейнкман, А.Я. Шик. ФТП, 10, 209 (1976).

[15] A.V. Marikutsa, M.N. Rumyantseva, E.A. Konstantinova, T.B. Shatalova, A.M. Gaskov. J. Phys. Chem. C, 118, 21541 (2014).

[16] Л.И. Рябова, Д.Р. Хохлов. Успехи физ. наук. 184 (1), 1033 (2014).

[17] Л.И. Рябова, Д.Р. Хохлов. Письма ЖЭТФ, 97 (12), 825 (2013).

Редактор Г.А. Оганесян

\section{Modification of photoconductivity spectra in composite structures $\mathrm{ZnO}-\mathrm{CdSe}$ quantum dots under additional photoexcitation}

\author{
K.A. Drozdov ${ }^{1}$, I.V. Krylov ${ }^{1}$, A.S. Chizhov ${ }^{2}$, \\ ${ }^{1}$ Lomonosov Moscow State University \\ (Department of Physics), \\ 119991 Moscow, Russia \\ 2 Lomonosov Moscow State University \\ (Department of Chemistry), \\ 119991 Moscow, Russia
} M.N. Rumyantseva ${ }^{2}$, L.I. Ryabova ${ }^{2}$, D.R. Khokhlov ${ }^{1}$

\begin{abstract}
The introduction of CdSe nanocrystals into the porous $\mathrm{ZnO}$ matrix results in the sensitization of the composite in the visible spectral range. The measurement of the spectral dependences of the photoconductivity with variable external illumination showed that they can undergo reversible changes. It is shown that the shape of the peak and the position of the local maximum of the photoconductivity corresponding to nanocrystals depend on the spectral distribution of the intensity of the incident radiation. The mechanisms responsible for the process are discussed.
\end{abstract}

